\title{
Synthesise of ZnO nano particle as an alternative catalyst for Photocatalytic degradation of brilliant red azo dye
}

\author{
Jayamadhava P. ${ }^{1}$, Sudhakara A. ${ }^{3,}$, Ramesha S. $^{2}$, Nataraja G. ${ }^{3}$ \\ ${ }^{1}$ Department of Chemistry, Shree Sharada R\&D Center, SS College, of AISECT UNIVERSITY, Chamarajpet, Bangalore, India- 560018 \\ ${ }^{2}$ R\&D Center Department of Chemistry, Rajarajeswari College of Engineering, Mysore Road, Bangalore, 560074 \\ ${ }^{3}$ Department of Chemistry, Jain Institute of Technology, Bada Cross, Davanagere, Karnataka, India, 577005
}

Email address:

jayamadhavap@gmail.com (Jayamadhava P.), suda.sagar@gmail.com (Sudhakara A.)

\section{To cite this article:}

Jayamadhava P., Sudhakara A., Ramesha S., Nataraja G. Synthesise of ZnO Nano Particle as an Alternative Catalyst for Photocatalytic Degradation of Brilliant Red Azo Dye. American Journal of Environmental Protection. Vol. 3, No. 6, 2014, pp. 318-322.

doi: $10.11648 /$ j.ajep.20140306.13

\begin{abstract}
A simple and a very convenient solution combustion method have been described to obtain $\mathrm{ZnO}$ nanoparticle. The band gap energy, particle size and morphology were studied by absorption spectra, XRD and SEM. The photocatalytic activity of synthesized $\mathrm{ZnO}$ nano particle on Brilliant red dye was studied by varying $\mathrm{pH}$, amount of catalyst and dye concentration respectively. According to the XRD the average crystallite size of $\mathrm{ZnO}$ was found to be $41 \mathrm{~nm}$ and the band gap energy of $\mathrm{ZnO}$ was found to be $3.2 \mathrm{eV}$. The photocatalytic degradation efficiency of this nanoparticle was found to be $100 \%, 98.6 \%$, and $87.3 \%$ for 25,50 at $75 \mathrm{mg} / \mathrm{L}$ dye concentrations respectively against Brilliant Red dye.
\end{abstract}

Keywords: Brilliant Red, Nano Particle, Photocatalyst, $\mathrm{ZnO}$

\section{Introduction}

Water is the wellspring of life and is the most important liquid in the world to maintain the plant and animal life. Since the two thirds of the earth's surface covered by water and human body consists of $75 \%$ of it, water is one of the prime element responsible for life on earth. Water is fouled due to the disposal of wastes generated from the various developmental activities and causes pollution problem. There are two choices to overcome these problems, i.e., normally prevention and control by adopting various strategies to minimize the waste generation and by different treatment methods. Liquid waste is of great concern because of their harmful effects. Industrial wastewater contains wide variety of materials of both organic and inorganic nature including toxic substances like dyes and pigments, which are usually discharged with or without treatment.

Since the beginning of industrialization, the variety and quantity of pollutants discharged into the environment have steadily increased. But the rates of development of waste production are not likely to diminish; efforts to control and dispose of wastes are also rising. Among the pollutants currently thousands of tons of organic dyes discharged from textile mills. Out of nearly 80,000 tons of annual production of dyes, $10-15 \%$ of the world product dye is lost during the dyeing process and is released in textile effluents [1]. These colored dye effluents create several environmental problems by releasing toxic and potential carcinogenic substances into the aqua sphere. This massive influx of untreated organic chemicals into the waterways not only introduces aesthetic concerns, but they promote eutrophication and adversely affect the environment [2]. Several studies have been carried out for biological, physical and chemical treatment of dye containing effluents [3]. Among these, biodegradation, adsorption, chlorination and ozonization are the most commonly used conventional methods. Dyes are usually resistant to aerobic degradation. Hence bio treatment alone has been found to be ineffective for the treatment of dye effluents [4]. On the other hand, physical methods such as flocculation, reverse osmosis and adsorption are not destructive and mainly create pollutant concentrated phases, and many of this process are not found economically feasible [5]. The use of heterogeneous photocatalytic treatment is more attractive for the degradation of organic dyes contrary to physical process; it can facilitate the complete mineralization of organic compounds to carbon dioxide, water and mineral acids [6-8]. Moreover, Photocatalysis does not require expensive oxidant and can be carried out at natural sunlight.

Hence, in the present work, the photocatalytic degradation 
of Brilliant Red (BR), a textile azo dye on synthesized $\mathrm{ZnO}$ nanoparticles under natural sunlight was investigated by varying other parameters such as initial dye concentration, solution $\mathrm{pH}$ and catalyst dosage.

\section{Experimental}

\subsection{Materials and Reagents}

Chemicals such as Zinc nitrate $\mathrm{Zn}\left(\mathrm{NO}_{3}\right)_{2} \cdot 6 \mathrm{H}_{2} \mathrm{O}$ and $\mathrm{NH}_{2}$ $\mathrm{CO} \mathrm{NH}_{2}$, all are of A.R grade obtained from Hi media chemicals Mumbai, and used without further purification. Brilliant Red (The molecular mass $=958, \lambda_{\max }=517 \mathrm{~nm}$ ) and distilled water was used for preparation of various solutions.

\subsection{Apparatus and Instruments}

A 119 UV-Vis single beam spectrophotometer from Systronics has been used for recording absorbance at $\lambda_{\max }$. Later the absorbance was recorded in UV-Vis spectrophotometer 169 (Systronics).

\subsection{Synthesis of Nanoparticles}

The photocatalyst $\mathrm{ZnO}$ was synthesized by solution combustion method. Stoichiometric compositions of Zinc nitrate and urea were calculated using the total oxidizing and reducing valencies of the components which serve as numerical coefficients for stoichiometric balance [9-10].

\subsection{Synthesis of $\mathrm{ZnO}$}

The stoichiometric amounts of Zinc nitrate, $\left(\mathrm{Zn}\left(\mathrm{NO}_{3}\right)_{2} \cdot 6 \mathrm{H}_{2} \mathrm{O}\right)$ (17.85g) was dissolved in a minimum quantity of water along with $\left(\mathrm{NH}_{2} \mathrm{CO} \mathrm{NH}\right)(6 \mathrm{~g})$ in a silica crucible (with a volume of $100 \mathrm{~cm}^{3}$ ). The mixture was introduced into the muffle furnace which was preheated at $600^{\circ} \mathrm{C}$. Initially the solution foils, boils and undergoes dehydration followed by decomposition with the evolution of gases $\left(\mathrm{N}_{2}\right.$ and $\left.\mathrm{CO}_{2}\right)$. Then, it burns to yield the residue. The gases evolved not only yield fine particles of metal oxides but also help to dissipate the heat which inhibits sintering of the product. Thus, combustion reaction was completed within a few minutes [11]. The combustion reaction for the synthesis of $\mathrm{ZnO}$ by the redox mixture method (urea) can be written as:

$$
\begin{gathered}
6 \mathrm{Zn}\left(\mathrm{NO}_{3}\right)_{2}+10 \mathrm{NH}_{2} \mathrm{CONH}_{2} \rightarrow 6 \mathrm{ZnO}+10 \mathrm{CO}_{2}+20 \mathrm{H}_{2} \mathrm{O}+ \\
16 \mathrm{~N}_{2}
\end{gathered}
$$

\subsection{XRD and SEM of Synthesized ZnO Nanoparticle}

The powdered sample of $\mathrm{ZnO}$ nanoparticle was examined by XRD and analysis was carried out on fresh sample to assess the purity of the expected phases and the degree of crystallization i.e., size, composition and crystal structure. XRD was performed by Rigaku diffractometer using $\mathrm{Cu}-\mathrm{K}_{\alpha}$ radiation $(1.5406 \AA)$ in a $\theta-2 \theta$ configuration. According to the $\mathrm{XRD}$ the average crystallite size of $\mathrm{ZnO}$ was found to be $41 \mathrm{~nm}$ (Fig. 1). Also, Figure 2 illustrates SEM photographs of single crystals of $\mathrm{ZnO}$. The photographs revealed plate like crystal morphology which looks like scattered. The individual plates are having sharp edges. The enlarged image shows the particles are attached on the other particles.

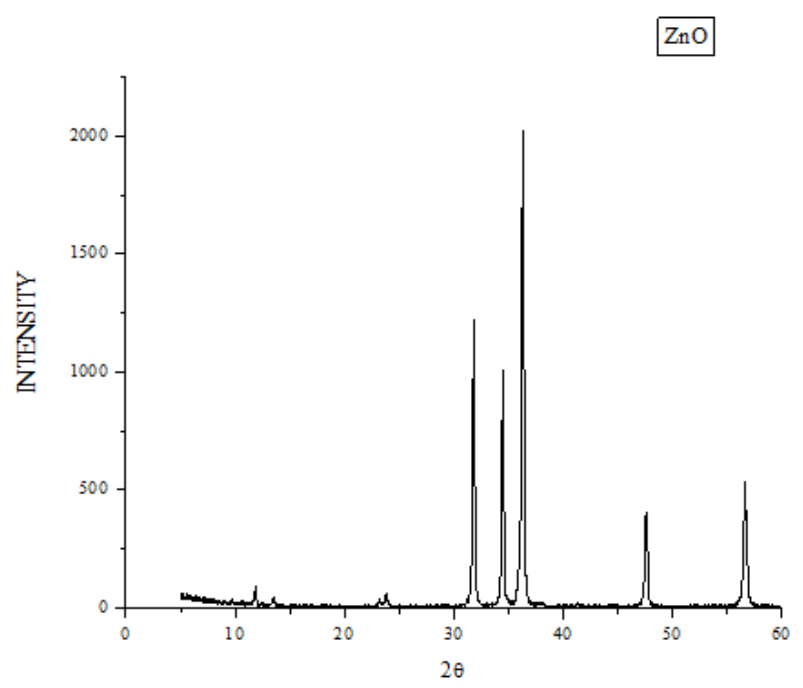

Fig 1. XRD of synthesized ZnO nanoparticle

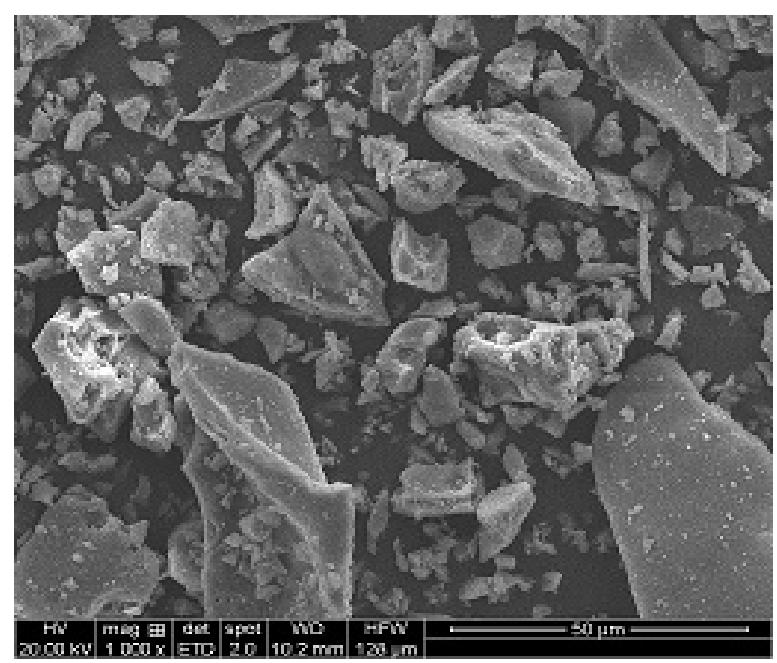

Fig 2. SEM micrographs of $\mathrm{ZnO}$

\subsection{UV Absorption Spectroscopy}

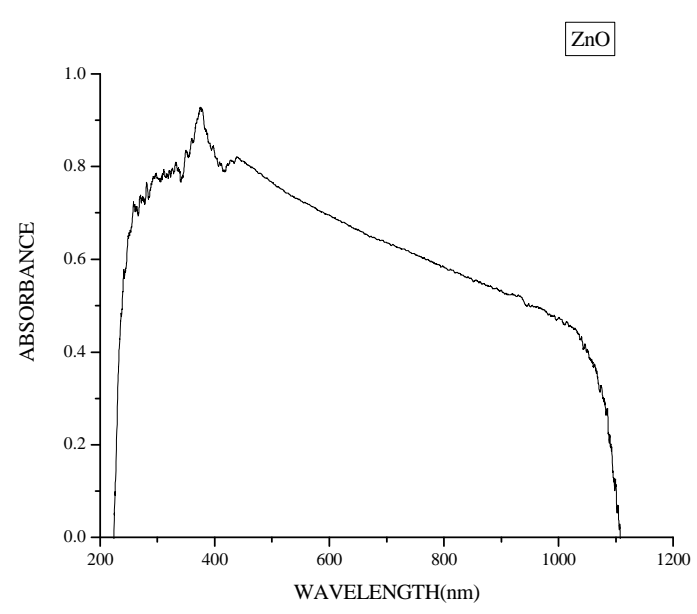

Fig 3. Absorption spectra of $\mathrm{ZnO}$ 
Absorption spectra of $\mathrm{ZnO}$ nanoparticle was recorded using a UV-Vis spectrophotometer over the wavelength range of 200-1200 nm at Nano Research Laboratory. From the spectrum, it has been inferred that $\mathrm{ZnO}$ nanoparticle has sufficient transmission in the entire visible and IR region. (Fig-3).

The band gap energy of the $\mathrm{ZnO}$ was calculated using the following simple conversion equation [12], the band gap equation is calculated using the Planck's equation as follows.

$$
\mathrm{e}=\mathrm{hc} / \lambda
$$

$\mathrm{h}=$ Planck's constant, $\mathrm{C}=$ Velocity of light, $\lambda=$ wavelength $\mathrm{h}=4.135 \times 10^{-15} \mathrm{eV}, \mathrm{C}=3 \times 10^{8} \mathrm{~m} / \mathrm{s}$

$$
\lambda=---\times 10^{-9} \mathrm{~nm}
$$

Band Gap Energy $(\mathrm{eV})=4.135 \times 10^{-15} \times 3 \times 10^{8} \times 10^{9}$

Band Gap Energy $(\mathrm{eV})=12.405 \times 10^{2} /$ wavelength $(\mathrm{nm})$

Band Gap Energy $(\mathrm{eV})=(1240 / 376)=3.2 \mathrm{eV}$

The band gap energy of $\mathrm{ZnO}$ found to be $3.2 \mathrm{eV}$.

\subsection{Procedure}

Photo degradation experiments were carried out with BR dye (Fig 4) concentration $50 \mathrm{mg} / \mathrm{L}$ prepared using distilled water. A known concentration of $\mathrm{ZnO}$ nanoparticle was added to beakers containing BR dye solution. The suspension $\mathrm{pH}$ values were adjusted at desired level using dilute $\mathrm{NaOH}$ and $\mathrm{H}_{2} \mathrm{SO}_{4}$ and then the $\mathrm{pH}$ values were measured with $\mathrm{pH}$ pen. After that, the beakers were kept in the sunlight. During irradiation, agitation was maintained to keep the suspension homogenous. The concentration of dye in each degraded sample was determined with UV-Vis spectrophotometer 169 (Systronics) at $\lambda_{\max }=517 \mathrm{~nm}$. The percentage of photo degradation $\mathrm{D}$ was determined by using the following equation ${ }^{6}$, where $\mathrm{C}_{0}$ is initial concentration of $\mathrm{BR}$ and $\mathrm{C}_{\mathrm{t}}$ is the concentration of $B R$ at time ' $t$ '.

$$
\mathrm{D}=\left(\frac{\mathrm{C}_{0}-\mathrm{C}_{\mathrm{t}}}{\mathrm{C}_{\mathrm{D}}}\right) \times 100
$$

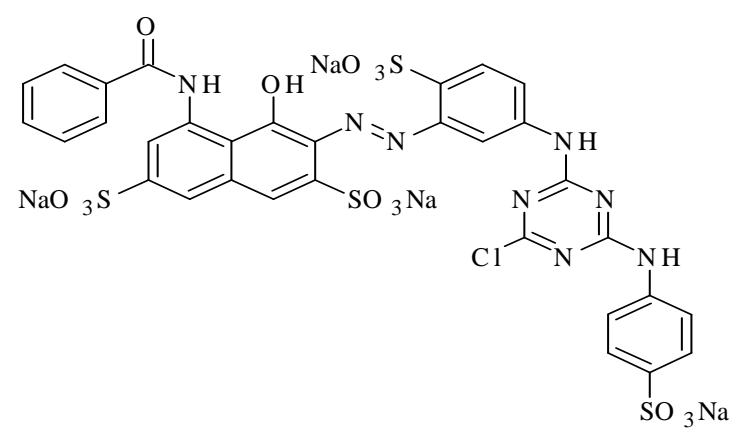

Fig 4. Structure of Brilliant Red

\section{Results and Discussion}

\subsection{Catalyst Type}

Initially, blank experiments were performed under direct sunlight without the addition of catalyst and no degradation was observed. To enhance the efficiency, different dose of catalysts were added. The results are shown in fig 5 , at dye concentration $=50 \mathrm{mg} / \mathrm{L}$, catalyst concentration $=0.4 \mathrm{~g} / 100 \mathrm{ml}$, initial solution $\mathrm{pH}=9$, and reaction time $=120 \mathrm{~min}$ respectively. The results showed that the $\mathrm{ZnO}$ nanoparticle exhibited higher photocatalytic activity. The similar result was also obtained in other studies with other type of azo dyes [13]. The decolourization result was explained on the basis of higher quantum efficiency of $\mathrm{ZnO}$. The band gap energy of $\mathrm{ZnO}$ was found to be $3.2 \mathrm{eV}$. The Sun light energy was found to be sufficient to cause excitation in $\mathrm{ZnO}$ nanoparticle [14]. Beside the band gap energy, the charge carrier density as well as the catalyst structure and the crystallinity may also have significant impact on the photocatalytic activity [15-16].

\subsection{Effect of Catalyst Concentration}

To determine the effect of the catalyst concentration, a series of experiments were carried by varying the amount of catalyst from 0.1 to $0.7 \mathrm{~g} / 100 \mathrm{ml}$ (dye concentration $=50 \mathrm{mg} / \mathrm{L}$, solution $\mathrm{pH}=9$ ) respectively. The photo degradation efficiency is as shown in Fig 5. As per the figure, for a constant reaction time $(120 \mathrm{~min})$, the degradation efficiency was found to increases sharply by increasing concentration up to $0.4 \mathrm{~g} / 100 \mathrm{ml}$, and then decreased gradually. At lower concentration, the catalyst surface and adsorption of light by the catalyst surface are the limiting factors and increase in catalyst greatly was enhances the degradation efficiency. On the other hand at higher concentration levels, the irradiation field inside the reaction medium was reduced due to the light scattering by catalyst particles [15].

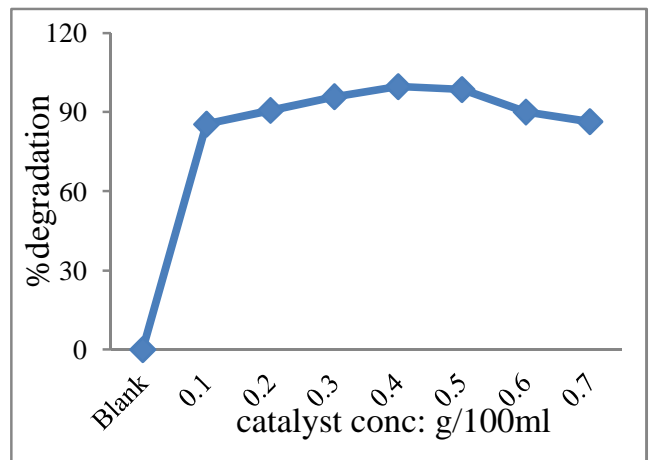

Fig 5. Effect of catalyst concentration on photocatalytic degradation of BR $(B R=50 \mathrm{mg} / \mathrm{L}, \mathrm{pH}=9$, Time $=120 \mathrm{~min})$

$$
\begin{aligned}
& \mathrm{ZnO}+\mathrm{h} v \rightarrow \quad\left(\mathrm{e}_{\mathrm{CB}}^{-}+\mathrm{h}_{\mathrm{VB}}^{+}\right) \\
& \mathrm{e}_{\mathrm{CB}}^{-}+\mathrm{O}_{2} \rightarrow \mathrm{O}_{2}{ }^{--} \text {. } \\
& \mathrm{H}_{2} \mathrm{O}+\mathrm{O}_{2}^{--} \rightarrow \mathrm{OOH}^{\cdot}+\mathrm{OH}^{-} \\
& 2 \mathrm{OOH}^{\cdot} \rightarrow \mathrm{O}_{2}+\mathrm{H}_{2} \mathrm{O}_{2} \\
& \mathrm{O}_{2}{ }^{--}+\text {dye } \rightarrow \text { dye-OO }
\end{aligned}
$$




$$
\begin{aligned}
& \mathrm{H}_{2} \mathrm{O}_{2}+\mathrm{O}_{2}^{--} \rightarrow \mathrm{OH}^{\cdot}+\mathrm{OH}^{-}+\mathrm{O}_{2} \\
& \mathrm{OH}^{*} / \mathrm{O}_{2}{ }^{--} / \mathrm{ZnO}^{*+}+\text { dye } \rightarrow \text { Dye degradation...... }
\end{aligned}
$$

It has been established that the photocatalysed degradation of organic matter in solution is initiated by the photo excitation of the semiconductor, followed by the formation of electron-hole pair on the surface of the catalyst. The mechanism of photocatalytic degradation for an azo dye are characterized by nitrogen to nitrogen double bonds $(\mathrm{N}=\mathrm{N})$. The color of azo dye is determined by the azo bonds and their associated chromophores and auxochromes. Azo bonds are the most active bonds in azo dye molecules and can be oxidized by positive hole or hydroxyl radical or reduced by electron in the conduction band. The cleavage of $\mathrm{N}=\mathrm{N}$ leads to the discoloration of dyes [17]. Mechanism of the photocatalytic degradation is as follows [18]. The mechanism of photocatalytic activity of $\mathrm{ZnO}$ nanoparticle can be predicted based on the equations as shown above. Under sunlight irradiation $\mathrm{ZnO}$ molecules get excited and transfer electron to the conduction band (Eq 1). Electron in the conduction band of $\mathrm{ZnO}$ can reduce molecular oxygen and produce the super oxide radical $\mathrm{O}_{2}$ ions (Eq 2). This radical may form hydrogen peroxide or organic peroxide in the presence of oxygen and organic molecule (Eq 3, 4, 5). Hydrogen peroxide can be generated in another path (Eq 6). Hydrogen peroxide can form hydroxyl radicals which are powerful oxidizing agents (Eq 7, 8). The radicals produced are capable of attacking dye molecules and degrade them (Eq 9) [19].

\subsection{Effect of $P H$}

In order to study the effect of $\mathrm{pH}$ on the degradation efficiency of $\mathrm{ZnO}$ catalyst, the experiments were conducted at various $\mathrm{pH}$ (ranging from 2 to 11). The results showed that $\mathrm{pH}$ significantly affected the degradation efficiency. As shown in fig.6, the degradation rate of BR increased from $70.5 \%$ to 98.6\% when the $\mathrm{pH}$ was increased from 2 to 9 and then decreased to $89.6 \%$ at $\mathrm{pH} 11$. The maximum degradation rate of BR was achieved at $\mathrm{pH} 9$. BR is an anionic dye which contains sulphonated groups. Its photocatalytic activity was maximum at $\mathrm{pH}$ 9. More efficient formation of hydroxyl radicals occurs in alkaline medium. Excess of hydroxyl anions increases the formation of $\mathrm{OH}$ radicals. These $\mathrm{OH}$ radicals are the main oxidizing species responsible for photocatalytic degradation. (Eq 7-8)[20]. But at above $\mathrm{pH} \mathrm{9,} \mathrm{the} \mathrm{decrease} \mathrm{in}$ the degradation efficiency can be explained on the basis of amphoteric nature of $\mathrm{ZnO}$ catalyst and the $\mathrm{ZnO}$ surface becomes negatively charged for higher $\mathrm{pH}$ values. This causes the electrostatic repulsion between the catalyst and negatively charged BR dye [21].

\subsection{Effect of Initial Dye Concentration}

The effect of initial dye concentration on the degradation efficiency was investigated by varying the initial dye concentration. The initial concentration of dye was varied from 25,50 and $75 \mathrm{mg} / \mathrm{L}$. $\mathrm{ZnO}$ resulted in $100 \%, 98.6 \%$, and $87.3 \%$ for 25,50 and $75 \mathrm{mg} / \mathrm{L}$ dye concentrations respectively

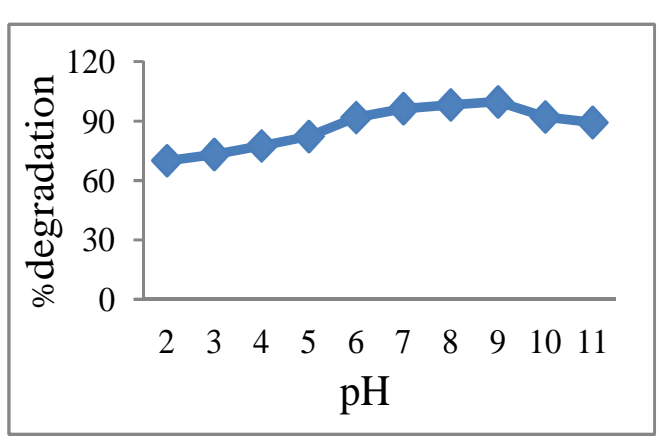

Fig 6. Effect of initial $\mathrm{pH}$ on photocatalytic degradation of $B R,(B R=50 \mathrm{mg} / \mathrm{L}$, $\mathrm{ZnO}=0.4 \mathrm{~g} / 100 \mathrm{ml}$, Time $=120 \mathrm{~min}$ )

These series of experiments illustrated that the degradation efficiency was inversely affected by the concentration (Fig. 7). The decrease in the degradation with an increase in dye concentration was ascribed to the equilibrium adsorption of dye on the catalyst surface which results in a decrease in the active sites. This phenomenon results in the lower formation of $\mathrm{OH}^{*}$ radicals which were considered as primary oxidizing agents of the organic dye [22]. On the other hand, according to Beer-Lambert law: as the initial dye concentration increases, the path length of photons entering the solution decreases. This results in the lower photon absorption on the catalyst particles, and consequently decreases the photocatalytic reaction rate [23].

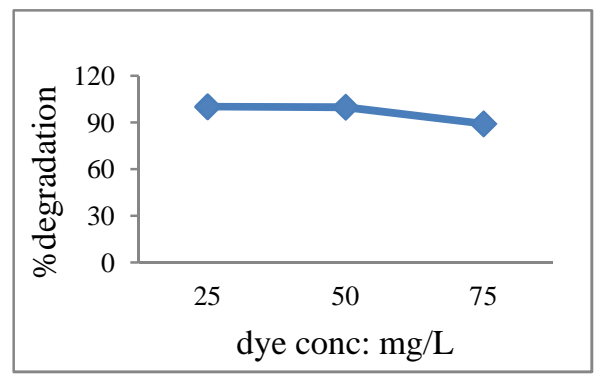

Fig 7. Effect of initial dye concentration on photocatalytic degradation of BR $(\mathrm{pH}=9, \mathrm{ZnO}=0.4 \mathrm{~g} / 100 \mathrm{ml}$, Time=120min $)$

\section{Conclusions}

A simple and very convenient solution combustion method was described to obtain $\mathrm{ZnO}$ nano particle. According to the XRD the average crystallite size of $\mathrm{ZnO}$ was found to be $41 \mathrm{~nm}$ and the band gap energy of $\mathrm{ZnO}$ was found to be $3.2 \mathrm{eV}$. The photocatalytic degradation efficiency of this $\mathrm{ZnO}$ nanoparticle was found to be $100 \%, 98.6 \%$, and $87.3 \%$ for 25,50 at 75 $\mathrm{mg} / \mathrm{L}$ dye concentrations respectively against Brilliant Red dye. The degradation efficiency increases with increase in $\mathrm{pH}$, and attaining maximum value at $\mathrm{pH}$ 9. The above $\mathrm{pH} 9$, the catalyst surface is negatively charged by means of adsorbed $\mathrm{OH}^{-}$ions, which causes electrostatic repulsion between catalyst and negatively charged BR decreases the degradation efficiency. Hence the experiment was proved that the $\mathrm{ZnO}$ having $41 \mathrm{~nm}$ in size and the band gap energy of $3.2 \mathrm{eV}$ was found to be very active catalyst and hence could be utilized in 
large scale for degradation of different azo dyes with suitable technology.

\section{Acknowledgements}

Authors are grateful to the Mr.NagenrdaPrasad. R., Director, R\&D Center SS College Bangalore, for valuable support for this research work and we also thank to Indian institute of science, Bangalore for spectral studies.

\section{Nomenclature}

$\begin{array}{ll}1 \mathrm{XRD} & \text { x ray Diffraction } \\ 2 \mathrm{SEM} & \text { Scanning Electron Microscopy } \\ 2 \mathrm{ZnO} & \text { Zink Oxide } \\ 3 \mathrm{Zn}\left(\mathrm{NO}_{3}\right)_{2} \cdot 6 \mathrm{H}_{2} \mathrm{O} & \text { Zinc nitrate }\end{array}$

\section{References}

[1] Ramesh Babu B, Parande AK, Raghu S and Prem Kumar T, Cotton Textile Processing: Waste Generation and Effluent Treatment, J Cott Sci, 2007,( 11): 141-153.

[2] Mehmet Kobya, Orhan Taner Can and Mahmut Bayramoglu, Treatment of textile wastewaters by electrocoagulation using iron and aluminum electrodes, J Hazard Mater, 2003,(100) : 163-178.

[3] Harrelkas F, Paulo A, Alves M M, El Khadir L, Zahraa O, Pons M N and van der Zee F P, Photocatalytic and combined anaerobic-photocatalytic treatment of textile dyes, Chemosphere, 2008, (72):1816-1822.

[4] Abdurrahman and Akyol, Treatment of paint manufacturing wastewater by electrocoagulation, Desalination, 2012, (285): 91-99.

[5] Kuo W S and Ho P H, Solar Photocatalytic decolorization of methylene blue in water, Chemosphere 2001, (45): 77-83.

[6] Daneshvar N, Salari D and Khataee A R, Photocatalytic degradation of azo dye acid red 14 in water on $\mathrm{ZnO}$ as an alternative catalyst to $\mathrm{TiO}_{2}$, J Photochem Photobiol A, 2004, (162): 317-322.

[7] Lianfeng Zhang, Tatsuo Kankia, Noriaki Sano and Atsushi Toyoda, Development of $\mathrm{TiO}_{2}$ photocatalyst reaction for water purification, Sep Purif Technol, 2003, (31): 105-10.

[8] Patrick Wilhelm and Dietmar Stephan, Photodegradation of Rhodamine $\mathrm{B}$ in aqueous solution via $\mathrm{SiO}_{2} @ \mathrm{TiO}_{2}$ nano-spheres, J Photochem Photobiol A Chemistry, 2007, (185): $19-25$

[9] Kashinath Patil C, Aruna S T and Tanu Mimani, Combustion synthesis: an update, Curr Opin Solid State Mater Sci, 2002, (6): 507-512.

[10] Gerko Oskam, Metal oxide nanoparticles: synthesis, characterization and application. J Sol Gel Sci Technol, 2006, (37): 161-164.
[11] Yogendra. K, Suneel Naik, Mahadevan K. M and Madhusudhana. N, A comparative study of photocatalytic activities of two different synthesized $\mathrm{ZnO}$ composites against Coralene Red F3BS dye in presence of natural solar light, J. Environ. Sci. Res., 2011,(1): 11-15.

[12] Sawant D K, Patil H M, Bhavsar D S, Patil J H and Girase K D, Structural and Optical Properties of Calcium Cadmium Tartrate, Arch Phys Res, 2011, (2): 67-73.

[13] Yogendra K, Suneel Naik, Mahadevan K M and Madhusudhana N, A comparative study of photocatalytic activities of two different synthesized $\mathrm{ZnO}$ composites against Coralene Red F3BS dye in presence of natural solar light, Int J Environ Sci Res, 2011,( 1): 11-15

[14] Ya-Li Song, Ji-Tai $\mathrm{Li}$ and $\mathrm{Bo}$ Bai, $\mathrm{TiO}_{2}$ Assisted Photodegradation of Direct Blue 78 in Aqueous Solution in Sunlight, Water Air Soil Pollut, 2010, (213):311-317.

[15] Madhusudhana N, Yogendra K, Mahadevan K M, Suneel Naik and Gopalappa $\mathrm{H}$, Photocatalytic degradation of Coralene dark Red 2B dye using calcium aluminate $\left(\mathrm{CaAl}_{2} \mathrm{O}_{4}\right)$ catalyst, J Environ Sci: An Ind J, 2011, (6):1-5.

[16] Barka N, Qourzal S, Assabbane A, Ait-Ichou Y, Nounah A, Lachheb $\mathrm{H}$ and Houas A, Solar Photocatalytic degradation of textile dyes on dynamic pilot plant using supported $\mathrm{TiO}_{2}$, Arab J Sci Eng, 2010, (35): 131-137.

[17] Akpan U G and Hameed B H, Parameters affecting the photocatalytic degradation of dyes using $\mathrm{TiO}_{2}$-based photocatalysts: A review, J Hazard Mater, 2009, (170):520-529

[18] Akyol A, Yatmaz H C and Bayramoglu M, Photocatalytic decolorization of Remazol Red $\mathrm{RR}$ in aqueous $\mathrm{ZnO}$ suspensions, Appl Catal B Environmental, 2004, (54): 19-24.

[19] Vinodgopal K and Prashant Kamat V, Photochemistry of textile azo dyes. Spectral characterization of excited state reduced and oxidized forms of Acid Orange 7, J Photochem Photobiol A Chem, 1994, (83): 141-146M. Young, The Technical Writer's Handbook. Mill Valley, CA: University Science, 198.

[20] Antoine P, Rousseau D D, Zoller L, Lang A, Munaut A V, Hatte, $\mathrm{C}$ and Fontugne $\mathrm{M}$, High resolution record of the last Interglacial glacial cycle in the Nussloch loess-paleosol sequences, Upper Rhine Area, Germany, Quaternary International,2001, (76/ 77): 211-229.

[21] Yurdakal S, Loddo V, Augugliaro V,Berber H, Palmisano G and Palmisano L, Photodegra dation of pharmaceutical drugs in aqueous $\mathrm{TiO}_{2}$ suspensions: Mechanism and kinetics, Catal Today, 2007, (129): 9-15.

[22] Mirkhani V, Tangestaninejad S, Moghadam M, Habibi M H and Rostami Vartooni A, Photocatalytic Degradation of Azo Dyes Catalyzed by $\mathrm{Ag}$ Doped $\mathrm{TiO}_{2}$ Photocatalyst, Journal of the Iranian Chemical Society, 2009,(6):578-587.

[23] Byrappa K, Subramani A K, Ananda S, Lokanatha Rai K M, Dinesh $\mathrm{R}$ and Yoshimura M, Photocatalytic degradation of Rhodamine B dye using hydrothermally synthesized $\mathrm{ZnO}$, Bulletin of Material Sciences, 2006,( 29): 433-438. 